\title{
Identification of Health Technology Management departments in Mexico"s State Health Services
}

\author{
By R. Ayala, E. Orencio
}

CENETEC-Salud, México

\begin{abstract}
Due to a lack of verifiable, reliable, and up-to-date official information, the National Center for Health Technology Excellence (CENETEC) carried out a survey of information to identify the organizational areas in charge of the verification and the development of Health Technology Management (HTM) that the State Health Services in Mexico are obliged to perform within each of the 32 States. It was determined that not all States had a department with a specific designation for HTM. Also, it seems the vast majority of existing areas are led by a biomedical engineering professional who responds to infrastructure planning area directives. These findings seek to promote a discussion on the need to standardize this type of service from State Health Services across the country.
\end{abstract}

Keywords - biomedical engineering, health technology management, public health services.

\section{INTRODUCTION}

The Mexican health system is composed of public and private sectors. The public sector includes social security institutions such as Instituto Mexicano del Seguro Social (IMSS), Institute of Security and Social Services of State Workers (ISSSTE), the health services of federal agencies Petróleos Mexicanos (PEMEX), the Secretary of National Defense (SEDENA), and the Secretary of Navy (SEMAR). On the other hand, there are health services for people who are not insured by any of the institutions previously mentioned. These people are cared for by health organizations under the control of the Federal Health Ministry and the 32 State Health Services. This is done with financial support from the Health Social Protection System known as Seguro Popular. ${ }^{1}$

Any organization that offers health services must carry out health technology management (HTM) which is defined as the "set of systematic procedures to provide and evaluate the appropriate, safe, effective, and costeffective technology in health care establishments, with the aim of ensuring the care and good use of the medical equipment by verifying its functionality, security, and availability to ensure effective access to health services." ${ }^{2}$ These processes fall into various operational, medical, or administrative departments but Biomedical Engineering 
(BME) services are considered to be the most appropriate for coordinating these tasks.

In Mexico, there is no formal or updated census of BME departments in hospitals. According to the Information Base of Health Establishments (CLUES ${ }^{3}$, a government information system), there is a register of 85 BME departments in hospitals from the State Health Ministries which represents only $12 \%$ of total coverage. Given this circumstance, the strategy has been to encourage the creation of central areas in the offices of each State to meet the needs of the HTM for all hospitals under its jurisprudence. However, there has been no formal register for those either.

Therefore, in 2018, the National Center for Health Technology Excellence (CENETEC), a Ministry of Health agency, through its BME department, undertook the task of running a situational diagnosis of the areas responsible for HTM in the 32 State Health Services. The goal was to identify the existing areas of opportunity related to the execution of the processes and the corresponding activities of the personnel in charge.

As this was the first time that an exercise of this nature had been carried out at the State Health Services, it was important to be able to have updated data to make an analysis of the situation and determine which areas were the responsibility of the HTMs. This would allow the further development of strategies to improve these processes in an efficient and responsible way.

\section{METHODS}

A questionnaire was prepared to identify the existence of areas or departments where HTM processes are involved in the State Health Services, their position within the organizational structure, as well as the human resources and materials they have available to them to carry out their tasks. The general items requested were as follows:

1. The State they are located

2. The data from their BME Department

3. The information regarding the person in charge of their BME Department

4. The area of the HTM processes they are part of
5. The infrastructure they have available to carry out their HTM processes

The questionnaire was given to personnel identified as possibly responsible for one or more HTM processes within the 32 State Health Services and the following relevant data obtained is outlined below.

The answers revealed:

- The organizational structure of the areas responsible for HTM.

- The name designation for each area responsible for HTM by State.

- The number of areas falling under the term "Biomedical Engineering."

- The profession of the person identified as being responsible for HTM and their duties.

- The identification of the areas that carry out HTM processes.

\section{RESULTS}

\section{Organizational Structure}

The 32 States responded with the information requested and it was possible to carry out the analysis to obtain the following results outlined below.

Twenty-four State Health Services (SESA) had an area using the term BME or something similar. In 8 SESAs an area with a similar designation could not be identified (Figure 1).

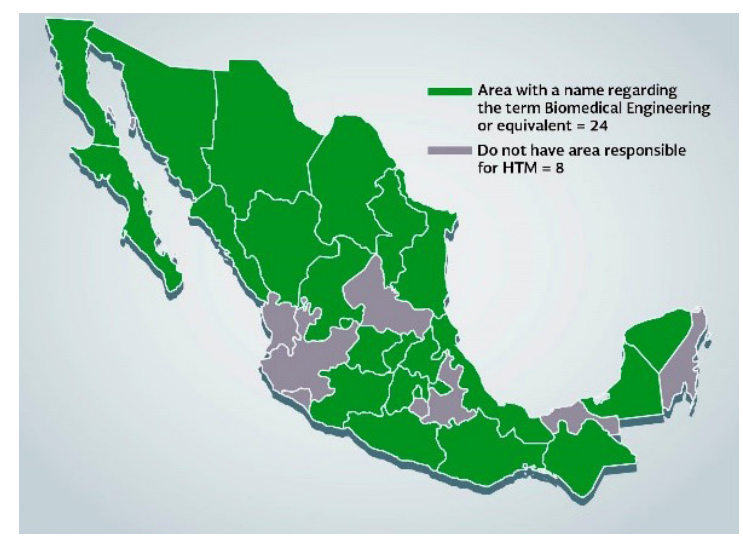

FIGURE 1. States with a department or area responsible for Health Technology Management. 
It was found that 20 different groups or departments had incorporated variations of the title "Biomedical Engineering." These included Director of Biomedical Engineering, Deputy Director of Biomedical Engineering, Department of Biomedical Engineering, Biomedical Engineering Coordination, Biomedical Services Coordination, and Biomedical Area. Other similar names used were Department of Technological Support to Hospitals, Department of Electromechanics, Department of Maintenance to Medical and Electromechanical Equipment, Department of Recovery of Medical Equipment, Department of Maintenance to Medical and Electromechanical Equipment, and Technology and Supplies Coordination. These designations suggest these people/departments have one or more HTM processes as part of their responsibilities.

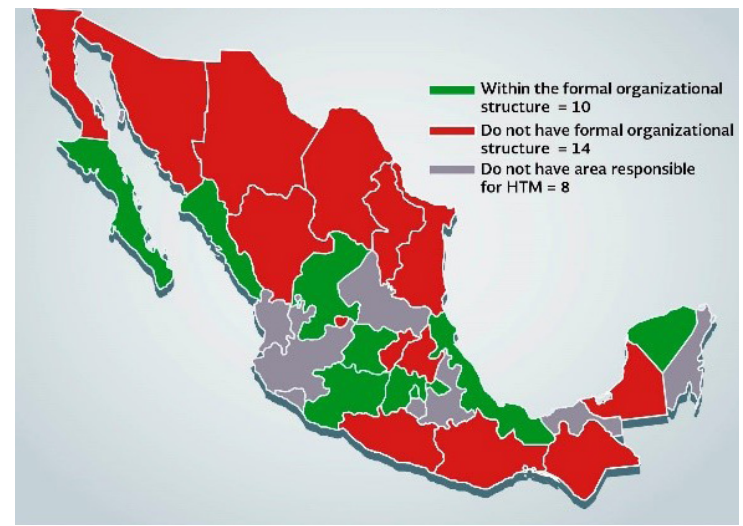

FIGURE 2. State Health Services that have an area that is responsible for HTM within their formal structure.

Ten of these departments were found within a formal organizational structure while 14 were not, and as shown in Figure 1, 8 did not have an area responsible for HTM. Figure 2 shows the States where the areas responsible for the HTM in the formal organizational structure existed within the State Health Services.

Data regarding which area (administrative, medical or planning) provided direction to the HTM are outlined below.

In 12 States, the HTM area depended on direction from a planning or infrastructure group; 6 States depended on direction from a medical department; 4 States depended on direction from an administrative branch; and 2 States have 2 HTMs being directed by 2 different groups (Figure 3 ).

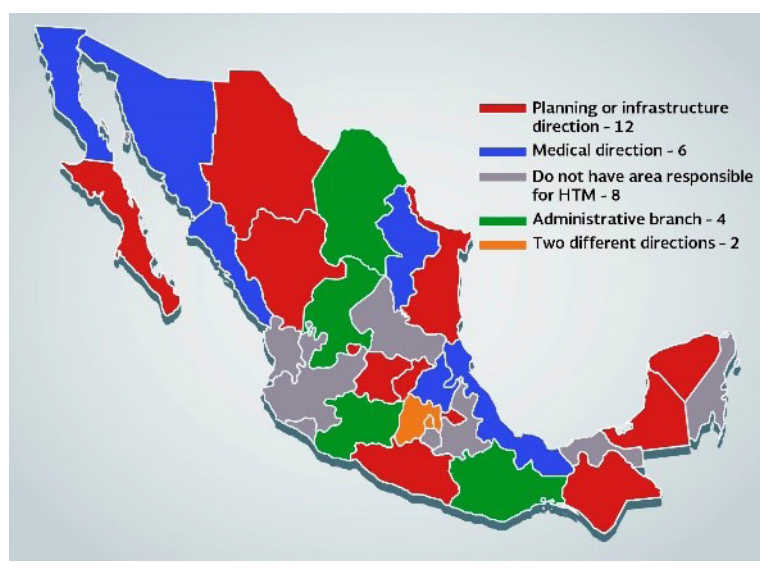

FIGURE 3. Health Technology Departments line of command.

\section{Human Resources}

The results shown in the graphs below include data from States that have the area responsible for HTM. Graph 1 shows the professions of those responsible for the areas reported. Please note the prevalence of the BME profession.

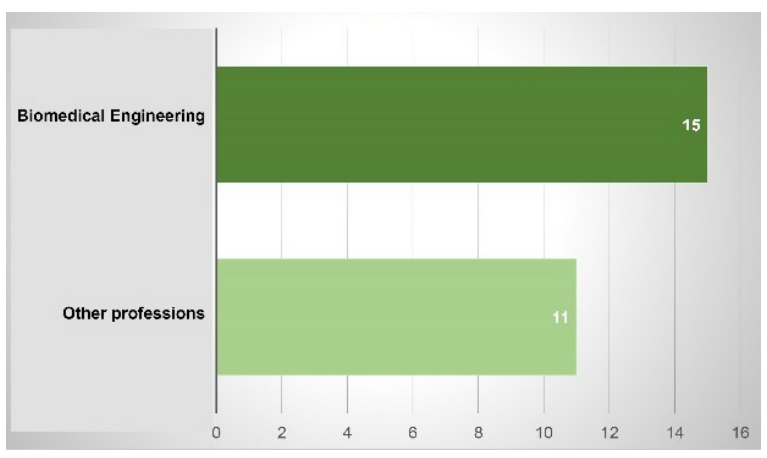

GRAPH 1. Profession of those responsible for Health Technology Management in State Health Services.

Graph 2 illustrates the type of job contract held by the person responsible for HTM. "Trust Staff" are those who have a formal contract, "Base Staff" are those who have a permanent contract, and "Eventual Staff" are those who have a short-period contract that may or may not be renewable.

Graph 3 presents the monthly salary for those responsible for HTM according to the level of position where the prevalence is higher than $\$ 20.000$ Mexican pesos. 
HTM Processes Attended

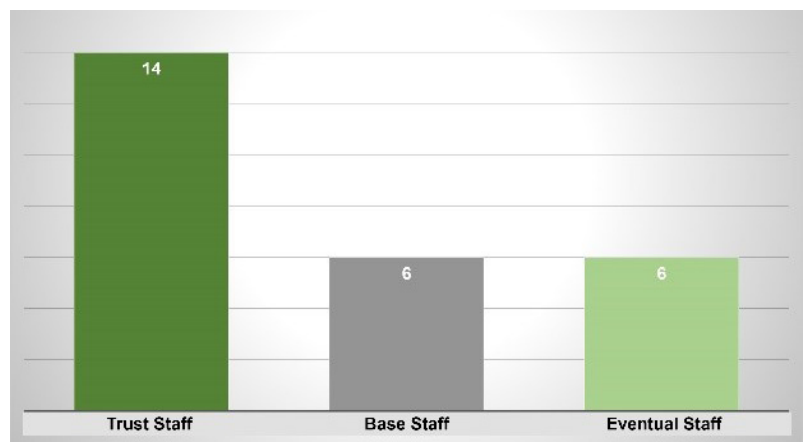

GRAPH 2. The type of job contract held by the person responsible for Health Technology Management.

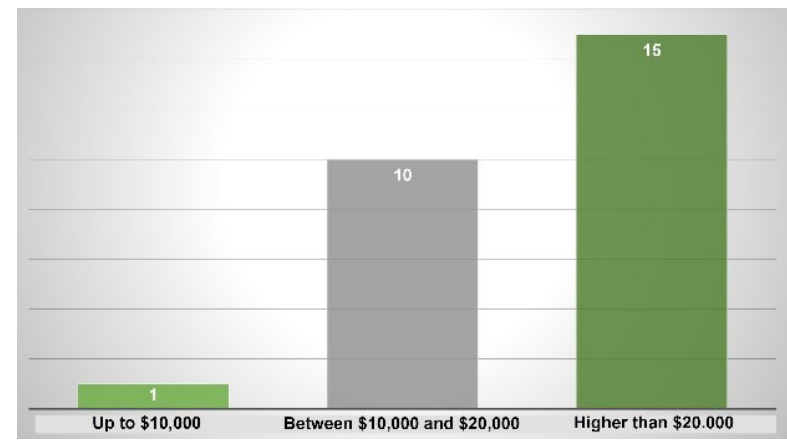

GRAPH 3. Salary level of the person responsible for Health Technology Management in State Health Services.

Graph 4 outlines the prevelence of tasks involving the the HTM processes and the execution of these processes and which areas in State Health Services carry them out. In 17 States the BME-related areas were the groups who executed most of the HTM processes, while in 10 other States this work was carried out by administrative areas.

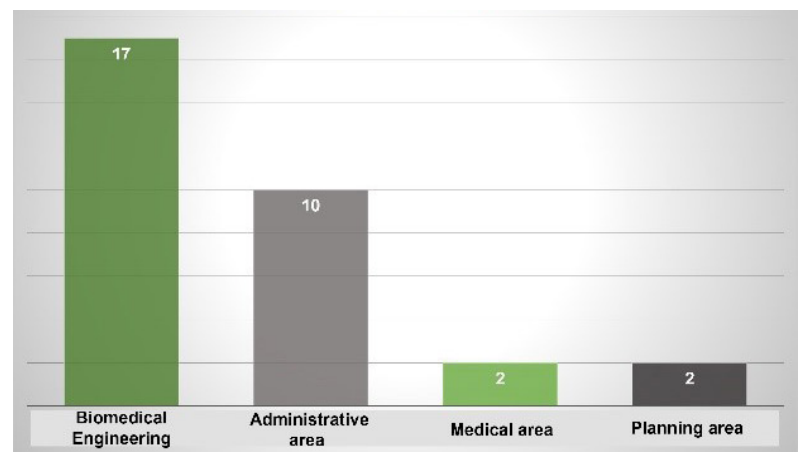

GRAPH 4. Prevalence in the execution of the Health Technology Management process in State Health Services.

\section{CONCLUSION}

In accordance with the results obtained it can be observed that even when 24 of 32 States have an area related to BME to carry out HTM functions, only $42 \%$ are positioned within the formal structure of the SESA and also their department name is often not consistent with other similar groups which can cause confusion.

Taking into consideration the reported areas, 57\% have a professionally educated BME as the person in charge. This indicates that this profession should be at the forefront for coordination of the HTM processes. In the same way, according to the data provided, (53\% of the cases), there is a high likelihood that the BME area has been designated as the group that should be responsible for carrying out the HTM processes. This was followed by the administrative area that had been designated in $31 \%$ of cases.

It could be said that the numbers are promising, but challenges still exist towards achieving effective coordination of the HTM processes in the public health sector.

The next step could be an analysis of the efficiency and effectiveness in the HTM processes when they are carried out by the specific areas chosen. Meanwhile, the material presented in this paper will allow a focused effort to continue formulating strategies associated with HTM that can promote safe, quality, efficient, and cost-effective access to health services.

\section{ACKNOWLEDGMENTS}

The authors wish to thank the personnel in the 32 SESA that kindly responded to the questionnaire and to the personnel in the BME area at CENETEC for their input and support. Thanks also to Sonia Tena for providing help in graphics design.

\section{REFERENCES}

1. Gómez-Dantés O, Sesma S, Becerril VM, Knaul FM, Arreola H, Frenk J. Sistema Health System in Mexico. Public Health Mex 2011;53 supl 2:S220-S232. Available at: http://www.scielo.org.mx/scielo.php?script=sci_ar ttext\&pid=S0036-36342011000800017 
2. National Center for Health Technology Excellence. Medical Equipment Management Glossary. México: CENETEC; 2016;107 first edition. Available at: http:// www.cenetec.salud.gob.mx/descargas/equipoMedico/ IB_Publicacion_Glosario_8_27Jun16.pdf

3. General Directorate of Health Information; Classification CLUES. Available at: http://www.dgis.salud.gob. $\mathrm{mx} /$ contenidos/intercambio/clues_gobmx.html 